\title{
Outcomes of off-pump versus on-pump coronary artery bypass grafting: Impact of preoperative risk
}

\author{
Marek Polomsky, MD, ${ }^{\mathrm{a}}$ Xia He, MS, ${ }^{\mathrm{b}}$ Sean M. O’Brien, PhD, ${ }^{\mathrm{b}}$ and John D. Puskas, MD, MSc ${ }^{\mathrm{a}}$
}

Background: It is unknown whether purported benefits of off-pump coronary artery bypass grafting are patientspecific within the Society of Thoracic Surgeons National Cardiac Database or dependent on center volume or operating surgeon.

\begin{abstract}
Methods: The Society of Thoracic Surgeons National Cardiac Database was queried for all patients undergoing nonemergency, isolated coronary artery bypass between January 1, 2005, and December 31, 2010, who had Predicted Risk of Mortality scores and participant/surgeon identifiers. Of these 876,081 patients ("all sites"), 210,469 underwent surgery at participant sites that had performed more than 300 off-pump and 300 on-pump coronary artery bypass operations during the 6-year study period ("high-volume sites"). Operative mortality, stroke, acute renal failure, mortality or morbidity, and prolonged postoperative length of stay were analyzed with conditional logistic models for all sites and for high-volume sites, stratified by participant center and surgeon, and adjusted for 30 variables that comprise the Society of Thoracic Surgeons coronary artery bypass grafting risk models.
\end{abstract}

Results: Off-pump coronary artery bypass was associated with a significant reduction in risk of death, stroke, acute renal failure, mortality or morbidity, and postoperative length of stay compared with on-pump coronary artery bypass after adjustment for 30 patient risk factors in the overall sample. This held true within highvolume centers. In the overall sample, there was a significant $(P<.05)$ interaction between off-pump coronary artery bypass and Predicted Risk of Mortality for death, stroke, acute renal failure, and mortality or morbidity.

Conclusions: Off-pump coronary artery bypass was associated with reduced adverse events compared with on-pump coronary artery bypass after adjustment for 30 patient risk factors and center and surgeon identity. Patients with higher Predicted Risk of Mortality scores had the largest apparent benefit. (J Thorac Cardiovasc Surg 2013;145:1193-8)

The interest in off-pump coronary artery bypass (OPCAB) has largely been driven by the increased awareness of the deleterious effects of cardiopulmonary bypass (CPB) and aortic manipulation. Although an abundance of literature comparing on-pump coronary artery bypass (ONCAB) and OPCAB exists, the optimal surgical approach remains in question. Although many surgeons and centers have adopted the off-pump technique, the majority of coronary artery bypass grafting (CABG) performed worldwide is on-pump. In $2010,21 \%$ of all primary CABG cases in the Society of Thoracic Surgeons (STS) National Adult Cardiac Surgery Database were performed with off-pump techniques. ${ }^{1}$

Several prospective, randomized trials including a metaanalysis of these trials have not shown an in-hospital mortality advantage for $\mathrm{OPCAB}$ compared with $\mathrm{ONCAB} .^{2-7}$ These

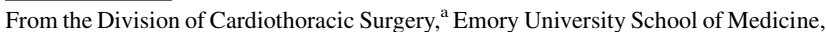
Atlanta, Ga; and Duke Clinical Research Institute, ${ }^{\mathrm{b}}$ Duke University, Durham, NC. Disclosures: Authors have nothing to disclose with regard to commercial support. Read at the 92nd Annual Meeting of The American Association for Thoracic Surgery, San Francisco, California, April 28-May 2, 2012.

Received for publication Sept 23, 2012; revisions received Jan 6, 2013; accepted for publication Feb 8, 2013.

Address for reprints: John D. Puskas, MD, MSc, Division of Cardiothoracic Surgery, Emory University, 550 Peachtree St, Medical Office Tower, Emory University Hospital Midtown, Atlanta, GA 30308 (E-mail: jpuskas@emory.edu). $0022-5223 / \$ 36.00$

Copyright (c) 2013 by The American Association for Thoracic Surgery http://dx.doi.org/10.1016/j.jtcvs.2013.02.002 trials are limited by a relatively low sample size, especially when trying to detect differences in an infrequent event, such as mortality, stroke, or myocardial infarction. Furthermore, these trials have enrolled predominantly lowrisk patients. Thus, it remains unclear which particular patient populations may benefit most from OPCAB

Numerous retrospective reviews of large databases have demonstrated a mortality benefit for OPCAB versus ONCAB. ${ }^{8-10}$ Such large real-world databases have the advantage of being adequately powered to detect significant differences in outcomes and are representative of a typical patient population spectrum. Registry studies include a spectrum of patients with mixed risk profiles. Ascertaining which patient subgroups may benefit from OPCAB could inform selective or increased adoption of OPCAB for that particular risk group. Recent studies of the STS Database have shown a mortality benefit of OPCAB for higher-risk patients. ${ }^{11,12}$

One major criticism of both randomized controlled trials and single-center observational analyses is that these studies are conducted at single centers with extensive off-pump experience. It is unclear what role hospital organizational structure in specialized centers, specialized technical skill, or OPCAB volume may play in particular outcomes after CABG. Relatively few studies have been conducted assessing center and surgeon volume with $\mathrm{OPCAB}$, and recent 


$$
\begin{array}{ll}
\text { Abbreviations and Acronyms } \\
\begin{array}{ll}
\text { ARF } & =\text { acute renal failure } \\
\text { CABG } & =\text { coronary artery bypass grafting } \\
\text { CI } & =\text { confidence interval } \\
\text { CPB } & =\text { cardiopulmonary bypass } \\
\text { euroSCORE } & =\text { European System for Cardiac } \\
& \text { Operative Risk Evaluation } \\
\text { MM } & =\text { mortality or morbidity } \\
\text { ONCAB } & =\text { on-pump coronary artery bypass } \\
\text { OPCAB } & =\text { off-pump coronary artery bypass } \\
\text { OR } & =\text { odds ratio } \\
\text { PLOS } & =\text { postoperative length of stay } \\
\text { PROM } & =\text { Predictive Risk of Mortality } \\
\text { RR } & =\text { relative risk } \\
\text { STS } & =\text { Society of Thoracic Surgeons }
\end{array}
\end{array}
$$

retrospective registry studies have found a mortality benefit with OPCAB in high-volume centers. ${ }^{13-15}$

The purpose of this study is to review the relative and absolute benefit of OPCAB versus ONCAB after adjusting for patient preoperative risk factors within the national database, while also controlling for surgeon and center.

\section{MATERIALS AND METHODS \\ Study Population}

The STS National Cardiac Database was queried for all patients undergoing nonemergency, isolated primary CABG between January 1, 2005, and December 31, 2010, who had complete data fields to calculate Predictive Risk of Mortality (PROM) scores and participant/surgeon identifiers. Of these 876,081 patients ("all sites"), 210,469 cases underwent surgery at participant sites that had performed more than 300 OPCAB and 300 ONCAB cases during the 6-year study period ("high-volume sites"). The distributions of patients' preoperative characteristics in both ONCAB and OPCAB groups are shown in Table 1 . The $P$ values for the hypothesis that no difference exists between 2 groups are calculated with chi-square tests for categoric variables and Wilcoxon rank-sum tests for continuous variables.

\section{Society of Thoracic Surgeons Predicted Risk of Mortality}

The PROM score was calculated for each patient using the risk factors and regression coefficients from the STS 2008 model. Four PROM groups were defined, such that the number of deaths in groups were similar (first quartile: $<1.5 \%$; second quartile: $1.5 \%-3.0 \%$; third quartile: $3.0 \%$ $6.0 \%$; fourth quartile: $>6.0 \%$ ). The mean (interquartile range) PROM was $1.73(0.52-1.92)$ overall, $1.69(0.52-1.89)$ in the ONCAB group, and $1.84(0.50-2.04)$ in the OPCAB group. In high-volume centers, the PROM was $1.75(0.52-1.94)$ overall, $1.74(0.53-1.93)$ in the ONCAB group, and $1.78(0.50-1.97)$ in the OPCAB group.

\section{Data Management and Statistical Analysis}

Outcomes after OPCAB versus ONCAB were compared by intent-totreat within the entire sample and within each PROM group both descriptively and by statistical models. Unplanned conversions from off-pump to on-pump were treated as off-pump cases. The effect of OPCAB versus ONCAB on operative mortality, stroke, acute renal failure (ARF), any mortality or morbidity (MM), and prolonged postoperative length of stay
(PLOS $>14$ days) was analyzed with conditional logistic models for all sites and for high-volume centers, stratified by participant or by surgeon. Unadjusted models with OPCAB as the only variable were fitted, as well as adjusted models including all 30 patient risk factors that comprise the STS isolated CABG 2008 mortality models and surgery date. ${ }^{16}$ Risk factors for the calculation of PROM included age, body surface area, creatinine, dialysis, ejection fraction, preoperative atrial fibrillation, congestive heart failure and New York Heart Association classifications, chronic lung disease, cardiovascular disease, cerebrovascular accident, diabetes and type (insulin or noninsulin dependent), number of diseased vessels, preoperative intra-aortic balloon pump/inotropes, shock, sex, immunosuppressive treatment, mitral insufficiency, percutaneous coronary intervention, peripheral vascular disease, timing of myocardial infarction, hypertension, aortic insufficiency, tricuspid insufficiency, aortic stenosis, left main disease, race, and time trend. Finally, a set of conditional logistic models tested the interaction term between the OPCAB and PROM groups to determine whether differences between OPCAB and ONCAB depended on PROM.

To further depict the relationship between the outcomes and PROM, generalized additive models were used with smoothing splines of PROM. The predicted outcome rates and their pointwise $95 \%$ confidence intervals (CIs) from these models were presented as figures to visually discriminate between the 2 treatment groups.

\section{RESULTS}

Table 2 displays the adjusted (by patient factors) and unadjusted odds ratios (ORs) and their $95 \%$ CIs of OPCAB versus ONCAB in the overall study sample and in highvolume sites. Both adjusted and unadjusted models were stratified by center. OPCAB was associated with significant reduction in risk of death, stroke, ARF, any MM, and PLOS greater than 14 days compared with ONCAB after adjustment for 30 patient risk factors in the overall sample. Within high-volume centers alone, OPCAB also was associated with a significant reduction in risk of death, stroke, ARF, any MM, and PLOS.

Table 3 displays the adjusted (by patient factors) and unadjusted ORs and their 95\% CIs of OPCAB versus ONCAB in the overall study sample and in high-volume sites. Both adjusted and unadjusted models were stratified by surgeon identity. The significant reduction in risk of death, stroke, ARF, MM, and PLOS of OPCAB compared with ONCAB was somewhat more pronounced after stratifying by surgeon at all sites and high-volume centers.

In the overall sample, there was a significant $(P<.05)$ interaction between OPCAB and PROM for death, stroke, ARF, and $\mathrm{MM}$, indicating that $\mathrm{OPCAB}$ was associated with a greater reduction in these adverse events in patients with higher PROM scores. Figure 1 displays the MM for all patients with OPCAB versus ONCAB at varying levels of PROM, showing the separation of lines with OPCAB having lower MM.

Table 4 shows the observed mortality and stroke in each PROM quartile. As the PROM quartile increases, the mortality and stroke rates are higher in both OPCAB and ONCAB. This effect is also present with high-volume centers. Yet in all PROM quartiles, the observed rates of death and stroke in OPCAB were lower compared with those in ONCAB. The magnitude of that difference increased with 
TABLE 1. Patient preoperative characteristics in the overall study sample

\begin{tabular}{|c|c|c|c|}
\hline Characteristic & $\begin{array}{c}\text { ONCAB } \\
n=689,943\end{array}$ & $\begin{array}{c}\text { OРCAB } \\
\mathrm{n}=\mathbf{1 8 6 , 1 3 8}\end{array}$ & $\begin{array}{c}P \\
\text { value }+\end{array}$ \\
\hline Age, y, mean (Q1, Q3) & $64.8(57.0-73.0)$ & $65.5(58.0-74.0)$ & $<.0001$ \\
\hline Male, n (\%) & $509,302(73.8)$ & $131,651(70.7)$ & $<.0001$ \\
\hline Black, n (\%) & $44,905(6.5)$ & $13,158(7.1)$ & $<.0001$ \\
\hline $\begin{array}{l}\text { Body surface area, } \mathrm{m}^{2}, \\
\text { mean }(\mathrm{Q} 1, \mathrm{Q} 3)\end{array}$ & $2.0(1.8-2.2)$ & $2.0(1.8-2.1)$ & $<.0001$ \\
\hline Diabetes, n (\%) & $275,304(39.9)$ & $70,462(37.8)$ & $<.0001$ \\
\hline Hypertension, n (\%) & $576,875(83.6)$ & $155,874(83.7)$ & .1908 \\
\hline Dialysis, n (\%) & $13,928(2.0)$ & $4676(2.5)$ & $<.0001$ \\
\hline CLD, n $(\%)$ & $152,242(22.1)$ & $41,766(22.4)$ & $<.0001$ \\
\hline PVD, n (\%) & $102,094(14.8)$ & $30,528(16.4)$ & $<.0001$ \\
\hline CVD, n (\%) & $95,274(13.8)$ & $28,233(15.2)$ & $<.0001$ \\
\hline CVA, n (\%) & $46,788(6.8)$ & $13,950(7.5)$ & $<.0001$ \\
\hline $\begin{array}{l}\text { Immunosuppressive } \\
\text { treatment, } \mathrm{n}(\%)\end{array}$ & $14,615(2.1)$ & $4824(2.6)$ & $<.0001$ \\
\hline Previous CABG, n (\%) & $27,346(4.0)$ & $6096(3.3)$ & $<.0001$ \\
\hline $\begin{array}{l}\text { Previous valve } \\
\quad \text { surgery, } \mathrm{n}(\%)\end{array}$ & $1910(0.3)$ & $618(0.3)$ & $<.0001$ \\
\hline $\begin{array}{l}\text { Previous other cardiac } \\
\text { surgery, } \mathrm{n}(\%)\end{array}$ & $11,340(1.6)$ & $3921(2.1)$ & $<.0001$ \\
\hline $\begin{array}{l}\text { Any previous } \mathrm{CV} \\
\quad \text { surgeries } \geq 1, \mathrm{n}(\%)\end{array}$ & $30,516(4.5)$ & $6976(3.7)$ & $<.0001$ \\
\hline Prior PCI, n (\%) & $161,245(23.4)$ & $46,330(24.9)$ & $<.0001$ \\
\hline $\begin{array}{l}\text { Acuity status }= \\
\text { elective, } \mathrm{n}(\%)\end{array}$ & $319,732(46.3)$ & $93,384(50.2)$ & $<.0001$ \\
\hline MI, n (\%) & $309,272(44.5)$ & $79,618(42.8)$ & $<.0001$ \\
\hline Angina, n (\%) & $506,154(73.4)$ & $135,532(72.8)$ & $<.0001$ \\
\hline $\begin{array}{l}\text { Cardiogenic } \\
\text { shock, n (\%) }\end{array}$ & $5315(0.8)$ & $1199(0.6)$ & $<.0001$ \\
\hline Resuscitation, n (\%) & $3201(0.5)$ & $775(0.4)$ & .0065 \\
\hline Arrhythmia, n (\%) & $53,536(7.8)$ & $15,1910(8.5)$ & $<.0001$ \\
\hline $\begin{array}{l}\text { Preoperative IABP, } \\
\text { n }(\%)\end{array}$ & 40,294 (5.8) & $8987(4.8)$ & $<.0001$ \\
\hline CHF, n (\%) & $98,245(14.2)$ & $26,960(14.4)$ & .0090 \\
\hline $\begin{array}{l}\text { CHF NYHA class IV, } \\
\mathrm{n}(\%)\end{array}$ & $27,108(3.9)$ & $7481(4.0)$ & .0767 \\
\hline $\begin{array}{l}\text { No. of diseased } \\
\quad \text { coronary } \\
\quad \text { vessels }=3, \mathrm{n}(\%)\end{array}$ & $546,559(79.2)$ & $119,220(64.0)$ & $<.0001$ \\
\hline $\begin{array}{l}\text { Left main disease } \\
\quad>50 \%, \mathrm{n}(\%)\end{array}$ & $214,321(31.1)$ & $53,226(28.6)$ & $<.0001$ \\
\hline $\mathrm{EF}, \%$, mean $(\mathrm{Q} 1, \mathrm{Q} 3)$ & $51.2(45.0-60.0)$ & $52.0(45.0-60.0)$ & $<.0001$ \\
\hline Aortic stenosis, n (\%) & $12,221(1.8)$ & $4148(2.2)$ & $<.0001$ \\
\hline Mitral stenosis, n (\%) & $2399(0.3)$ & $691(0.4)$ & .0959 \\
\hline Tricuspid stenosis, n (\%) & $557(0.1)$ & $177(0.1)$ & .0461 \\
\hline Pulmonic stenosis, $\mathrm{n}(\%)$ & $1135(0.2)$ & $278(0.1)$ & .1822 \\
\hline
\end{tabular}

+ Null hypothesis: variables have the same distribution (ie, same proportion for binary variables, comparable values for continuous variables) in OPCAB and ONCAB groups. Wilcoxon rank-sum test is used for continuous variables, and Pearson's chi-square test is used for categoric variables. $O N C A B$, On-pump coronary artery bypass; $O P C A B$, off-pump coronary artery bypass; $C L D$, chronic lung disease; $P V D$, peripheral vascular disease; $C V D$, cardiovascular disease; $C V A$, cerebrovascular accident; $C A B G$, coronary artery bypass grafting; $C V$, cardiovascular; $P C I$, percutaneous coronary intervention; $M I$, myocardial infarction; $I A B P$, intra-aortic balloon pump; $C H F$, congestive heart failure; NYHA, New York Heart Association; $E F$, ejection fraction. increasing PROM. The proportion of OPCAB was $20.8 \%$ in the group with the lowest PROM and increased to $25.8 \%$ in the group with the highest PROM. Large-volume centers had a slightly lower rate of death than lower-volume centers. The relative lower rates of death and stroke with OP$\mathrm{CAB}$ versus $\mathrm{ONCAB}$ were similar in high-volume centers compared with all centers.

\section{DISCUSSION}

This retrospective review of the STS National Adult Cardiac Database analyzed 876,081 patients who underwent coronary bypass grafting between January 1, 2005, and December 31, 2010. Of these, 210,469 patients underwent operation at high-volume centers where more than 300 $\mathrm{OPCAB}$ and $\mathrm{ONCAB}$ cases were performed during this time period. This is the largest series to date to examine outcomes after $\mathrm{CABG}$ with and without $\mathrm{CPB}$.

In this intent-to-treat analysis, OPCAB was associated with reduced adverse events compared with ONCAB after adjustment for 30 patient risk factors. OPCAB was associated with a significant reduction in risk of death, stroke, ARF, any $\mathrm{MM}$, and prolonged PLOS compared with CABG on CPB.

Numerous prospective, randomized trials have not shown an in-hospital mortality advantage for OPCAB versus ON$\mathrm{CAB}$, although these trials have shown an advantage with regard to transfusion requirements, myocardial enzyme release, intensive care unit and hospital length of stay, duration of mechanical ventilation, and cost. ${ }^{2-6}$ In the largest multicenter randomized trial to date comparing OPCAB with ONCAB (4752 patients) at 79 centers in 19 countries, Lamy and colleagues ${ }^{17}$ found no difference in the 30-day rate of primary composite outcome of death, myocardial infarction, stroke, or renal requiring dialysis. OPCAB was associated with reduced rates of transfusions, reoperation for perioperative bleeding, respiratory complications, and acute kidney injury, but resulted in an increased risk of early revascularization. The trial was conducted by surgeons with expertise in OPCAB or ONCAB, yet the majority of patients were of mixed-risk (European System for Cardiac Operative Risk Evaluation [euroSCORE] 3-5) and ejection fraction $>50 \%$. In a meta-analysis of 37 randomized trials (3369 patients), no significant differences were found for 30-day mortality between OPCAB and ONCAB (OR, 1.02; 95\% CI, 0.58-1.80). ${ }^{7}$ As opposed to large-scale observational studies, failure to show any differences in randomized trials can be attributed to low sample size, which can increase the probability of a type II error, as well as a predominance of low- or intermediate-risk patients.

In the present large retrospective analysis, within all PROM quartiles, OPCAB was associated with a significantly reduced risk of death and stroke. Moreover, the magnitude of the apparent risk reduction increased with increasing PROM.

As such, the perceived benefits of OPCAB may become more apparent in high-risk patients, especially those with 
TABLE 2. Off-pump versus on-pump in the overall study sample and in large centers, adjusted (by patient factors), and unadjusted odds ratios and their $95 \%$ confidence intervals

\begin{tabular}{|c|c|c|c|c|c|c|c|c|}
\hline \multirow[b]{4}{*}{ Outcome } & \multicolumn{8}{|c|}{ Models stratified by center identity } \\
\hline & \multicolumn{4}{|c|}{ All sites } & \multicolumn{4}{|c|}{ High-volume sites } \\
\hline & \multicolumn{2}{|c|}{ Not adjusted by patient RF } & \multicolumn{2}{|c|}{ Adjusted by patient RF } & \multicolumn{2}{|c|}{ Not adjusted by patient RF } & \multicolumn{2}{|c|}{ Adjusted by patient RF } \\
\hline & OR $(95 \%$ CI $)$ & $P$ value & OR $(95 \%$ CI $)$ & $P$ value & OR $(95 \%$ CI $)$ & $P$ value & OR $(95 \%$ CI $)$ & $P$ value \\
\hline Operative mortality & $0.95(0.91-1.00)$ & .0709 & $0.89(0.84-0.94)$ & $<.0001$ & $0.86(0.79-0.93)$ & $<.0001$ & $0.84(0.77-0.91)$ & $<.0001$ \\
\hline Stroke & $0.66(0.62-0.71)$ & $<.0001$ & $0.66(0.62-0.71)$ & $<.0001$ & $0.66(0.60-0.72)$ & $<.0001$ & $0.66(0.60-0.73)$ & $<.0001$ \\
\hline Renal failure & $0.83(0.80-0.86)$ & $<.0001$ & $0.80(0.77-0.84)$ & $<.0001$ & $0.82(0.77-0.86)$ & $<.0001$ & $0.82(0.78-0.87)$ & $<.0001$ \\
\hline Operative MM & $0.78(0.77-0.80)$ & $<.0001$ & $0.78(0.76-0.79)$ & $<.0001$ & $0.77(0.74-0.79)$ & $<.0001$ & $0.78(0.75-0.80)$ & $<.0001$ \\
\hline Prolonged PLOS & $0.82(0.79-0.84)$ & $<.0001$ & $0.77(0.74-0.79)$ & $<.0001$ & $0.79(0.76-0.83)$ & $<.0001$ & $0.77(0.73-0.80)$ & $<.0001$ \\
\hline
\end{tabular}

Both adjusted and unadjusted models were stratified by center. Adjusted analyses adjust for patient-level characteristics; the list of factors is the same as the STS 2008 isolated CABG model, plus surgery date. $R F$, Risk factor; $O R$, odds ratio; $C I$, confidence interval; $M M$, mortality or morbidity; $P L O S$, postoperative length of stay.

chronic obstructive pulmonary disease, renal insufficiency, and advanced atheromatous disease of the ascending aorta subject to aortic clamping, manipulation, and cannulation with CPB. Large-scale registries and observational studies are sufficiently powered to detect significant differences in adverse outcomes across a broad patient population and especially high-risk patients. Hannan and colleagues, ${ }^{8}$ in 49,830 patients from the New York State registry who underwent a risk-adjusted analysis (Cox proportional hazard models and propensity analysis), showed that patients undergoing OPCAB had a significantly lower 30-day mortality than those undergoing ONCAB (adjusted OR, 0.81; $95 \% \mathrm{CI}, 0.68-0.97 ; P=.0022) .{ }^{8}$ In another large California registry study, $\mathrm{Li}$ and colleagues ${ }^{9}$ also demonstrated a significant reduction in propensity-adjusted operative mortality with OPCAB compared with ONCAB $(2.59 \%$; $95 \%$ CI, $2.52-2.67$ vs $3.22 \%, 95 \%$ CI, 3.17-3.27). An intention-to-treat retrospective analysis of 42,477 patients from the STS National Database showed a reduction in risk-adjusted operative mortality (adjusted OR, 0.83; $P=.03$ ), as well as numerous morbidity outcomes favoring patients undergoing OPCAB. ${ }^{11}$ To the contrary, assessing 63,000 patients in the Nationwide Inpatient Sample administrative (rather than clinical) database, Chu and colleagues $^{18}$ found no difference in hospital mortality between $\mathrm{OPCAB}$ and $\mathrm{ONCAB}(3.0 \%$ vs $3.2 \%, P=.14)$.
In retrospective series, more favorable outcomes have been reported after OPCAB compared with ONCAB in patients with left ventricular dysfunction, left main disease, end-stage renal disease on dialysis, previous sternotomy, advanced age, previous stroke, and female gender. ${ }^{11,19-21}$ In a large retrospective cohort (14,766 patients), Puskas and colleagues ${ }^{12}$ reported that patients in the highest risk quartile had a significant reduction in hospital mortality with OPCAB compared with ONCAB $(3.2 \%$ vs $6.7 \% ; P<.0001$; OR, $0.45 ; 95 \%$ CI, $0.33-0.63 ; P<.0001)$. There was no difference in operative mortality between OPCAB and ONCAB for patients in the lower 2 risk quartiles. However, patients with an STS predicted risk of mortality $>2.5 \%$ had an apparent survival advantage with OPCAB. That study provides further support that OPCAB may disproportionately benefit high-risk patients. The apparent mortality benefit shown for OPCAB in large retrospective analyses seems to be driven by a disproportionate benefit experienced by the higher-risk patients within real-world databases.

As randomized trials have begun to focus on higher-risk patients, results have demonstrated more favorable outcomes for OPCAB compared with ONCAB. In a trial by Moller and colleagues $^{22}$ (the Best Bypass Surgery Trial), 341 high-risk patients (euroSCORE $\geq 5$ ) underwent multivessel OPCAB or ONCAB. ${ }^{22}$ The difference in event rates for the composite of major adverse cardiac and cerebrovascular events at 30

TABLE 3. Off-pump versus on-pump in the overall study sample and in large centers, adjusted (by patient factors), and unadjusted odds ratios and their $95 \%$ confidence intervals

\begin{tabular}{|c|c|c|c|c|c|c|c|c|}
\hline \multirow[b]{4}{*}{ Outcome } & \multicolumn{8}{|c|}{ Models stratified by surgeon identity } \\
\hline & \multicolumn{4}{|c|}{ All sites } & \multicolumn{4}{|c|}{ High-volume sites } \\
\hline & \multicolumn{2}{|c|}{ Not adjusted by patient RF } & \multicolumn{2}{|c|}{ Adjusted by patient RF } & \multicolumn{2}{|c|}{ Not adjusted by patient RF } & \multicolumn{2}{|c|}{ Adjusted by patient RF } \\
\hline & OR $(95 \%$ CI $)$ & $P$ value & OR $(95 \%$ CI $)$ & $P$ value & OR $(95 \%$ CI $)$ & $P$ value & OR $(95 \%$ CI $)$ & $P$ value \\
\hline Operative mortality & $0.93(0.88-0.99)$ & .0231 & $0.85(0.80-0.90)$ & $<.0001$ & $0.76(0.68-0.85)$ & $<.0001$ & $0.75(0.68-0.84)$ & $<.0001$ \\
\hline Stroke & $0.63(0.58-0.68)$ & $<.0001$ & $0.63(0.58-0.68)$ & $<.0001$ & $0.63(0.55-0.71)$ & $<.0001$ & $0.63(0.56-0.72)$ & $<.0001$ \\
\hline Renal failure & $0.79(0.76-0.83)$ & $<.0001$ & $0.77(0.73-0.81)$ & $<.0001$ & $0.71(0.65-0.76)$ & $<.0001$ & $0.73(0.67-0.79)$ & $<.0001$ \\
\hline Operative MM & $0.77(0.75-0.79)$ & $<.0001$ & $0.77(0.75-0.79)$ & $<.0001$ & $0.72(0.70-0.75)$ & $<.0001$ & $0.74(0.71-0.77)$ & $<.0001$ \\
\hline Prolonged PLOS & $0.83(0.80-0.86)$ & $<.0001$ & $0.77(0.74-0.80)$ & $<.0001$ & $0.77(0.73-0.82)$ & $<.0001$ & $0.74(0.70-0.79)$ & $<.0001$ \\
\hline
\end{tabular}

Both adjusted and unadjusted models were stratified by surgeon identity. Adjusted analyses adjust for patient-level characteristics; the list of factors is the same as the STS 2008 isolated CABG model, plus surgery date. $R F$, Risk factor; $O R$, odds ratio; $C I$, confidence interval; $M M$, mortality or morbidity; PLOS, postoperative length of stay. 


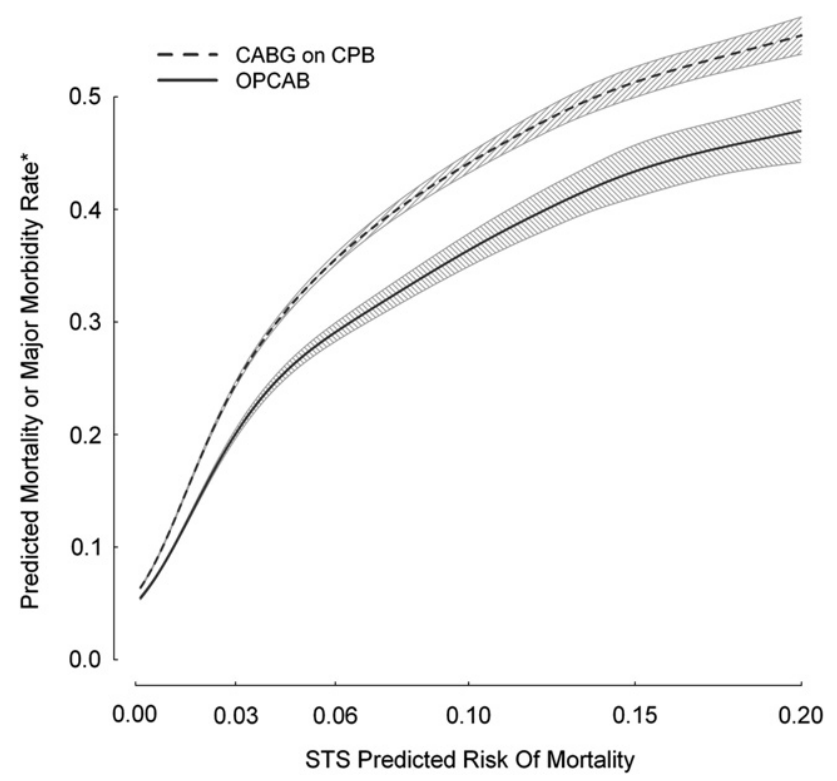

FIGURE 1. Predicted risk of MM by PROM in OPCAB and ONCAB. * Y-axis shows the predicted event rates and CIs from generalized additive models fitted with MM as outcome and PROM as the only predictor. $C A B G$, Coronary artery bypass grafting; $C P B$, cardiopulmonary bypass; $O P C A B$, off-pump coronary artery bypass; STS, Society of Thoracic Surgeons.

days was not statistically significant ( $15 \%$ vs $18 \%$; relative risk [RR], $0.83 ; 95 \% \mathrm{CI}, 0.52-1.34)$, but there was a trend toward reduced all-cause 30-day mortality in the OPCAB group (3.4\% vs $6.7 \%$; RR, $0.51 ; 95 \%$ CI, 0.19-1.34). A lack of statistical difference may have been related to the small sample size. In an interim analysis of 411 high-risk patients in a multicenter, prospective, randomized trial (on-off study), Lemma and colleagues ${ }^{23}$ reported that the composite primary end point (operative mortality, myocardial infarction, stroke, renal failure, reoperation for bleeding, and adult respiratory distress syndrome) was significantly lower in the OPCAB group $(5.8 \%$ vs $13.3 \%, P=.010) .{ }^{23}$ All patients enrolled in the trial had a euroSCORE of 6 or more, with a mean of 8 , and the operations were performed by surgeons with extensive training and experience in $\mathrm{OPCAB}$ and $\mathrm{ONCAB}$ techniques, a feature lacking in some previous trials not showing a difference.

The findings in the present analysis of the STS National Cardiac Database show that adjusted risk of stroke was decreased with OPCAB compared with ONCAB. There have been no randomized prospective trials that have shown a statistically significant reduction in stroke with $\mathrm{OPCAB}$ compared with ONCAB. However, numerous large retrospective analyses have shown that OPCAB may be associated with a reduced risk-adjusted incidence of stroke compared with ONCAB. ${ }^{8,20,24}$ In a recent meta-regression analysis of 59 randomized trials encompassing $8961 \mathrm{pa}$ tients, Afilalo and colleagues ${ }^{25}$ showed a significant $30 \%$ reduction in the occurrence of postoperative stroke with OPCAB (RR, 0.70; 95\% CI, 0.49-0.99). Although the mechanisms responsible for the observed reduction in postoperative stroke have not been well defined, eliminating aortic manipulation with cannulation and application of a crossclamp, assessing aortic atherosclerosis by intraoperative epiaortic ultrasonography, and using clampless proximal anastomotic devices may decrease the number of intraoperative embolic events. The STS Database does not have data on the rate of use of clampless techniques until the most recent version of the database, which is after the end of our study period.

In the present study, the advantage of OPCAB over ONCAB in reduction of mortality, stroke, ARF, MM, and PLOS changed only minimally after stratification by center and by surgeon. This indicates that the benefit of OPCAB is largely independent of centers and surgeons within the STS National Cardiac Database. The relative reduction of risk of death and stroke with OPCAB versus ONCAB was similar in high-volume centers compared with all centers across all PROM quartiles. Konety and colleagues ${ }^{14}$ assessed the effect of surgical volume on outcomes after OPCAB $(\mathrm{n}=26,011)$ and $\mathrm{ONCAB}(\mathrm{n}=99,344)$ in 124 California

TABLE 4. Number of mortality and stroke cases and observed event rates by Predicted Risk of Mortality groups

\begin{tabular}{|c|c|c|c|c|c|c|c|c|c|c|c|c|}
\hline \multirow[b]{3}{*}{ PROM group } & \multicolumn{6}{|c|}{ All patients } & \multicolumn{6}{|c|}{ Patients from large centers } \\
\hline & \multicolumn{3}{|c|}{ Off-pump } & \multicolumn{3}{|c|}{ On-pump } & \multicolumn{3}{|c|}{ Off-pump } & \multicolumn{3}{|c|}{ On-pump } \\
\hline & No. case & No. operation & $\%$ & No. case & No. operation & $\%$ & No. case & No. operation & $\%$ & No. case & No. operation & $\%$ \\
\hline \multicolumn{13}{|l|}{ Mortality } \\
\hline 1 & 721 & 122,355 & 0.6 & 2977 & 466,405 & 0.6 & 269 & 53,295 & 0.5 & 516 & 87,251 & 0.6 \\
\hline 2 & 746 & 35,010 & 2.1 & 2898 & 131,147 & 2.2 & 300 & 14,798 & 2.0 & 535 & 25,096 & 2.1 \\
\hline 3 & 762 & 18,788 & 4.1 & 2877 & 63,606 & 4.5 & 289 & 7749 & 3.7 & 560 & 12,503 & 4.5 \\
\hline 4 & 881 & 9985 & 8.8 & 2878 & 28,785 & 10.0 & 338 & 4041 & 8.4 & 558 & 5736 & 9.7 \\
\hline \multicolumn{13}{|l|}{ Stroke } \\
\hline 1 & 641 & 122,355 & 0.5 & 3594 & 466,405 & 0.8 & 293 & 53,295 & 0.5 & 746 & 87,251 & 0.9 \\
\hline 2 & 404 & 35,010 & 1.2 & 2375 & 131,147 & 1.8 & 185 & 14,798 & 1.3 & 487 & 25,096 & 1.9 \\
\hline 3 & 329 & 18,788 & 1.8 & 1622 & 63,606 & 2.6 & 148 & 7749 & 1.9 & 328 & 12,503 & 2.6 \\
\hline 4 & 233 & 9985 & 2.3 & 933 & 28,785 & 3.2 & 94 & 4041 & 2.3 & 199 & 5736 & 3.5 \\
\hline
\end{tabular}

PROM, Predicted Risk of Mortality. 
hospitals, using the California Patient Discharge Database. For hospitals in the highest percent $\mathrm{OPCAB}$ volume quartile, adjusted mortality and complication rates were significantly lower compared with ONCAB (OR, 0.50; 95\% CI, 0.41$0.61 ; P<.001)$. However, in the lowest percent OPCAB volume quartile, outcomes between OPCAB and ONCAB were similar. In a recent study examining the Nationwide Inpatient Sample database from 2003 to 2007, Lapar and colleagues ${ }^{15}$ showed that there was an estimated $5 \%$ decrease in the absolute probability of death among 270,230 patients undergoing OPCAB when performed by surgeons with the highest volume, compared with a 3\% decrease in 439,253 patients undergoing ONCAB. Yet the effect of surgeon volume was significantly less than other operative and patient risk factors, questioning the contribution of surgeon volume toward mortality. Although the benefit of OPCAB may be increased with higher relative hospital volume, it can also be safely performed across a variety of hospitals with differing experience levels. In addition to surgeon skill, hospital organizational structures, such as skilled first and second assistants, surgical technicians, operating room nurses, intensive care unit resources, and anesthesia personnel, may be important factors.

\section{Study Limitations}

The present study is limited by its retrospective, observational nature. Despite adjusting for 30 patient preoperative factors, as well as surgeon and hospital identity, there is potential for residual confounding from factors not captured in the STS Database. Although the STS National Database collected data across multiple institutions, the expertise and interest may vary across centers. Major limitations of retrospective analyses within the STS Database are selection bias in the choice of OPCAB versus ONCAB and potential underreporting of unplanned conversion from off-pump to on-pump. In addition, the outcomes evaluated in our analysis are short-term outcomes, and long-term outcomes, such as rates of revascularization, freedom from symptoms, and long-term mortality, were not evaluated in our study. Despite the rigorous nature of the data collected within the STS Database, it may not be possible to adjust for all confounding variables, known and unknown, that may affect the choice of surgical procedure and patient outcomes.

\section{CONCLUSIONS}

In this analysis of the STS National Databse, OPCAB was associated with reduced risk of death, stroke, acute renal failure, mortality or morbidity, and prolonged length of stay compared with ONCAB after adjustment for 30 patient risk factors and stratifying for both center and surgeon identity. OPCAB had a significantly greater reduction in these adverse events in patients with higher PROM scores. The benefit of OPCAB, therefore, may be more apparent in high-risk patients.

\section{References}

1. Society of Thoracic Surgeons. Society of Thoracic Surgeons National Adult Cardiac Database Harvest Report, 2011 Harvest 1. April 2011.

2. Nathoe HM, van Dijk D, Jansen EW, et al. A comparison of on-pump and off-pump coronary bypass surgery in low-risk patients. N Engl J Med. 2003;348:394-402.

3. Puskas JD, Williams WH, Duke PG, et al. Off-pump coronary artery bypass grafting provides complete revascularization with reduced myocardial injury, transfusion requirements, and length of stay: a prospective randomized comparison of two hundred unselected patients undergoing off-pump versus conventional coronary artery bypass grafting. J Thorac Cardiovasc Surg. 2003;125:797-808.

4. Khan NE, De Souza A, Mister R, et al. A randomized comparison of off-pump and on-pump multivessel coronary-artery bypass surgery. N Engl J Med. 2004;350:21-8.

5. Angelini GD, Culliford L, Smith DK, et al. Effects of on- and off-pump coronary artery surgery on graft patency, survival, and health-related quality of life: longterm follow-up of 2 randomized controlled trials. J Thorac Cardiovasc Surg. 2009; 137:295-303.

6. Shroyer AL, Grover FL, Hattler B, et al. On-pump versus off-pump coronary-artery bypass surgery. N Engl J Med. 2009;361:1827-37.

7. Cheng DC, Bainbridge D, Martin JE, et al. Does off-pump coronary artery bypass reduce mortality, morbidity, and resource utilization when compared with conventional coronary artery bypass? A meta-analysis of randomized trials. Anesthesiology. 2005;102:188-203.

8. Hannan EL, Wu C, Smith CR, et al. Off-pump versus on-pump coronary artery bypass graft surgery: differences in short-term outcomes and in long-term mortality and need for subsequent revascularization. Circulation. 2007;116:1145-52.

9. Li Z, Yeo KK, Parker JP, et al. Off-pump coronary artery bypass graft surgery in California, 2003 to 2005. Am Heart J. 2008;156:1095-102.

10. Puskas JD, Cheng DM, Knight JM, et al. Off-pump versus conventional coronary artery bypass grafting: a meta-analysis and consensus statement from the 2004 ISMICS Consensus Conference. Innovations. 2005;1:3-27.

11. Puskas JD, Kilgo PD, Kutner M, et al. Off-pump techniques disproportionately benefit women and narrow the gender disparity in outcomes after coronary artery bypass surgery. Circulation. 2007;116:I192-9.

12. Puskas JD, Thourani VH, Kilgo P, et al. Off-pump coronary artery bypass disproportionately benefits high-risk patients. Ann Thorac Surg. 2009;88:1142-7.

13. Birkmeyer JD, Siewers AE, Finlayson EV, et al. Hospital volume and surgical mortality in the United States. N Engl J Med. 2002;346:1128-37.

14. Konety SH, Rosenthal GE, Vaughan-Sarrazin MS. Surgical volume and outcomes of off-pump coronary artery bypass graft surgery: does it matter? J Thorac Cardiovasc Surg. 2009;137:1116-23.e1.

15. Lapar DJ, Mery CM, Kozower BD, et al. The effect of surgeon volume on mortality for off-pump coronary artery bypass grafting. J Thorac Cardiovasc Surg. 2012;143:854-63.

16. Shahian DM, O'Brien SM, Filardo G, et al. The Society of Thoracic Surgeons 2008 cardiac surgery risk models: part 3-valve plus coronary artery bypass grafting surgery. Ann Thorac Surg. 2009;88:S43-62.

17. Lamy A, Devereaux PJ, Prabhakaran D, et al. Off-pump or on-pump coronaryartery bypass grafting at 30 days. $N$ Engl J Med. 2012;366:1489-97.

18. Chu D, Bakaeen FG, Dao TK, et al. On-pump versus off-pump coronary artery bypass grafting in a cohort of 63,000 patients. Ann Thorac Surg. 2009;87:1820-7.

19. Dewey TM, Herbert MA, Prince SL, et al. Does coronary artery bypass graft surgery improve survival among patients with end-stage renal disease? Ann Thorac Surg. 2006;81:591-8.

20. Halkos ME, Puskas JD, Lattouf OM, et al. Impact of preoperative neurologic events on outcomes after coronary artery bypass grafting. Ann Thorac Surg. 2008;86:504-10.

21. Jarral OA, Saso S, Athanasiou T. Off-pump coronary artery bypass in patients with left ventricular dysfunction: a meta-analysis. Ann Thorac Surg. 2011;92: 1686-94.

22. Moller CH, Perko MJ, Lund JT, et al. Three-year follow-up in a subset of highrisk patients randomly assigned to off-pump versus on-pump coronary artery bypass surgery: the Best Bypass Surgery trial. Heart. 2011;97:907-13.

23. Lemma MG, Coscioni E, Tritto FP, et al. On-pump versus off-pump coronary artery bypass surgery in high-risk patients: operative results of a prospective randomized trial (on-off study). J Thorac Cardiovasc Surg. 2012;143:625-31.

24. Sharony R, Grossi EA, Saunders PC, et al. Propensity case-matched analysis of off-pump coronary artery bypass grafting in patients with atheromatous aortic disease. J Thorac Cardiovasc Surg. 2004;127:406-13.

25. Afilalo J, Rasti M, Ohayon SM, et al. Off-pump vs on-pump coronary artery bypass surgery: an updated meta-analysis and meta-regression of randomized trials. Eur Heart J. 2012;33:1257-67. 